\title{
First-Line Antiretroviral Therapy With A Protease Inhibitor Versus Non-Nucleoside Reverse Transcriptase Inhibitor And Switch At Higher Versus Low Viral Load In Hiv-Infected Children: An Open-Label, Randomised Phase 2/3 Trial
}

\author{
The PENPACT-1 (PENTA 9 / PACTG 390) Study Team ${ }^{*}$
}

\begin{abstract}
Background-Randomised long-term comparisons between protease inhibitor(PI) and nonnucleoside reverse transcriptase inhibitor(NNRTI) first-line antiretroviral therapy(ART) and viral load(VL) switch criteria have never been undertaken in HIV-infected children.

Methods-PENPACT-1(ISRCTN73318385) assessed long-term effectiveness of ART-naïve children from Europe and North/South America initiating 2NRTIs+PI vs 2NRTIs+NNRTI, and switch to second-line at $\mathrm{VL} \geq 1000 \mathrm{c} / \mathrm{ml}$ vs $\geq 30000 \mathrm{c} / \mathrm{ml}$ in a randomised open-label factorial design. The primary outcome was VL change between baseline and 4 years.
\end{abstract}

Results-266 children were randomised(66 PI-1000, 65 PI-30000, 68 NNRTI-1000, 67 NNRTI-30000), and 263 analysed(3 NNRTI-30000 excluded); median age 6.5(IQR:2.812.9)years; mean(SD) CD4 18\%(11); VL 5.1(0.8) $\log _{10} \mathrm{c} / \mathrm{ml}$. Median follow-up was 5.0(IQR:4.26.0)years; $188(71 \%)$ children were on first-line ART at trial end. For children starting second-line ART, median VLs at switch were $6720 \mathrm{c} / \mathrm{ml}$ vs $35712 \mathrm{c} / \mathrm{ml}$ in 1000 vs 30000 ; children in the 30000 group switched 41 weeks later, on average.

At 4 years, mean VL reductions were -3.16 vs $-3.31 \log _{10} \mathrm{c} / \mathrm{ml}$ for PI vs NNRTI(difference $\left.-0.15 \log _{10} \mathrm{c} / \mathrm{ml}, 95 \% \mathrm{CI}[-0.41,0.11] ; \mathrm{p}=0.26\right)$, and $-3.26 \mathrm{vs}-3.20 \log _{10} \mathrm{c} / \mathrm{ml}$ for $1000 \mathrm{vs}$ 30000 (difference $0.06 \log _{10} \mathrm{c} / \mathrm{ml}, 95 \% \mathrm{CI}[-0.20,0.32] ; \mathrm{p}=0.56$ ); $\mathrm{VL}$ was $<400 \mathrm{c} / \mathrm{ml}$ in $82 \% \mathrm{PI}$ vs $82 \%$ NNRTI, $\mathrm{p}=0.91$ and $83 \% 1000$ vs $80 \% 30000, \mathrm{p}=0.42$. Nine children with new CDC-C events, and 60 experiencing grade $3 / 4$ adverse events were balanced across randomisations. PI resistance was uncommon and no increase in NRTI resistance occurred in PI-30000 compared to PI-1000. In contrast, NNRTI resistance was selected early (similar in 1000 and 30000), and $~ 10 \%$ more children accumulated NRTI mutations in NNRTI-30000 than NNRTI-1000.

Conclusion-There was no difference between initiating ART with PI or NNRTI-based regimens; both achieved good long-term virological outcomes. Delayed switching on NNRTI-

() 2011 Elsevier Ltd. All rights reserved.

Corresponding author: Linda Harrison, MRC Clinical Trials Unit, 222 Euston Road, London, NW1 2DA, UK. Tel +44 (0) 207670

4811. Fax +44 (0) 207670 4685. lijh@ctu.mrc.ac.uk.

*See Appendix for Writing Committee

Conflict of Interest

SF received honoraria for serving on Scientific Advisory Boards and/or lectures from Abbott Molecular Inc and Roche Molecular Systems. MH is a paid Data and Safety Monitoring Board member for Boehringer Ingelheim, Medicines Development, Pfizer and Tibotec. RM is a paid Data and Safety Monitoring Board member for Gilead Sciences. DMG and ASW are paid Data and Safety Monitoring Board members for Tibotec. No other member of the Writing Committee has a conflict of interest.

Publisher's Disclaimer: This is a PDF file of an unedited manuscript that has been accepted for publication. As a service to our customers we are providing this early version of the manuscript. The manuscript will undergo copyediting, typesetting, and review of the resulting proof before it is published in its final citable form. Please note that during the production process errors may be discovered which could affect the content, and all legal disclaimers that apply to the journal pertain. 
based ART increases NRTI, but not NNRTI resistance, which occurs early irrespective of viral load threshold. However, delayed switching on PI-based ART may be reasonable where future drug options are limited as the risk of NRTI/PI resistance appears minimal.

\section{Introduction}

In the early 2000s, opinion was divided amongst paediatricians regarding the choice of a protease inhibitor(PI)(1) or non-nucleoside reverse transcriptase inhibitor(NNRTI)(2) containing first-line antiretroviral therapy(ART) for HIV-infected children. In addition, because of limited choice of antiretroviral drugs for children and relatively high failure rates on first-line regimens(3-6), there was concern that if switch to second-line occurred early (soon after virological failure with low viral load(VL)), treatment options would quickly be exhausted. While increased numbers of antiretroviral drugs have more recently become available, children starting ART early in life (as now recommended by all paediatric guidelines(7-9)) will need to receive ART into adulthood, and hence potentially receive chronic therapy for many decades.

Direct comparisons of the long-term clinical outcome of PI and NNRTI-based first-line ART have never been undertaken in children and only one small randomised trial of switching at different VL thresholds has been performed in adults(10). PENPACT-1 was designed to address the long-term outcome of both these strategies in a randomised trial with a factorial design. The trial was developed as a collaboration between the Paediatric European Network for Treatment of AIDS(PENTA) and the Pediatric AIDS Clinical Trials Group(PACTG/IMPAACT) in the USA.

\section{Methods}

\section{Trial Design}

PENPACT-1 was an international multicentre phase II/III, randomised, open-label, $2 \times 2$ factorial trial (ISRCTN73318385). HIV-1 infected children from centres in Europe and North/South America, who were either antiretroviral naïve or had received $<56$ days of antiretroviral drugs to reduce mother-to-child transmission (excluding single-dose nevirapine, protocol amendment), and required ART, were eligible. Children were simultaneously randomised in a 1:1 ratio to (a) initiate ART with 2NRTIs plus a PI or 2NRTIs plus an NNRTI, and (b) switch from first-line to second-line ART at a VL threshold of $\geq 1000 \mathrm{c} / \mathrm{ml}$ or $\geq 30000 \mathrm{c} / \mathrm{ml}$.

First-line ART was defined as the initial randomised regimen, allowing drug substitutions (ideally within the same class) for non-virologic reasons (e.g. toxicity). Children switched to second-line ART if the randomised VL threshold $(<1000$ or $<30000 \mathrm{c} / \mathrm{ml})$ was not achieved by week 24, or if an initial decline in VL by week 24 was followed by VL rebound at/above their randomised level, confirmed within 2-5 weeks. Switch to second-line ART was also required if a new $\mathrm{CDC}$ stage $\mathrm{C}$ event occurred at/after 24 weeks of ART. Children randomised to initial PI-containing first-line ART were strongly encouraged to switch to NNRTI-containing second-line ART and vice-versa.

Children were assessed at screening (week -2), randomisation (week 0), weeks 2, 4, 8, 12, 16,24 , and 12 weekly until the last randomised child reached 4 years of follow-up. The protocol was approved by the relevant ethics committee/Institutional Review Board for each participating centre. All parents/guardians and children as appropriate gave written consent/ assent. 


\section{Randomisation}

Randomisation was stratified by age ( $<$ or $\geq 3$ years), region (PENTA or PACTG centre), and by exposure to perinatal ART to reduce mother-to-child transmission. The computergenerated sequentially numbered randomisation lists (with variable block sizes) were preprepared by the Trial Statistician and securely incorporated within the PENTA and PACTG databases, allowing access to the next number but not the whole list. Site personnel from participating centres randomised children by faxing/phoning the PENTA trials unit or completing an online checklist at the PACTG trials unit.

\section{Primary and Secondary Outcomes}

The primary outcome was change in $\log _{10}$ HIV-1 RNA VL between baseline (mean of VLs at screening and randomisation) and four years (mean of VLs at weeks 192 and 204). VL measurements for the primary comparison were performed in two centralised laboratories using Abbott RealTime (lower cut-off 40c/ml). Local VLs were used when samples were unavailable for central testing.

Secondary outcomes were regimen switch, change in CD4\% from baseline to four years, VL $<400 \mathrm{c} / \mathrm{ml}$ at week 24 on first-line ART, VL $<400 \mathrm{c} / \mathrm{ml}$ at 4 years, continued VL suppression (never confirmed $>400 \mathrm{c} / \mathrm{ml}$ ) on first-line ART, failure of second-line ART (defined as confirmed VL $>30000 \mathrm{c} / \mathrm{ml}$ or discontinuation of second-line ART), grade $3 / 4$ adverse events (non-HIV related), new CDC stage $\mathrm{C}$ events and resistance (performed on stored samples in two central laboratories). Baseline resistance tests were performed on samples within 84 days before randomisation. Resistance during follow-up was measured on samples with: (a) last VL>1000c/ml while on first-line ART prior to switch; (b) confirmed VL $>1000 \mathrm{c} / \mathrm{ml}$ prior to re-suppression (to ensure a fair comparison between the 1000 and 30000 groups). Additionally, resistance testing was performed on samples with $\mathrm{VL}>1000 \mathrm{c} / \mathrm{ml}$ at 4 years and trial end. Major resistance mutations were defined according to the December 2009 IASUSA guidelines(11) and high-level resistance to specific antiretroviral drugs by the Stanford scoring system(12).

\section{Sample Size}

The planned sample size of 256 children was based on a standard deviation of $0.7 \log _{10} \mathrm{c} / \mathrm{ml}$ for the mean change in VL from baseline to 4 years, and provided $90 \%$ power to detect a difference for each main comparison (PI vs NNRTI; 1000 vs 30000$)$ of $0.3 \log _{10} \mathrm{c} / \mathrm{ml}(5 \%$ two-sided significance level) assuming $10 \%$ of VLs were missing at 4 years and all were detectable. If $40 \%$ of VLs were undetectable there was $90 \%$ power to detect a difference of $0.5 \log _{10} \mathrm{c} / \mathrm{ml}(13)$. The trial was not specifically powered to detect interactions between the PI vs NNRTI and 1000 vs 30000 randomisations.

\section{Data and Safety Monitoring}

Interim data on safety, adherence to randomised strategies, and efficacy of PI vs NNRTI and 1000 vs 30000 were reviewed regularly by an independent Data and Safety Monitoring Board that met approximately annually (5 meetings in total). There were no formal statistical rules for recommending stopping or modifying the trial.

\section{Statistical Analysis}

All analyses used intention-to-treat; statistical tests were two-sided and adjusted for stratification factors. Primary comparisons of change in VL from baseline to 4 years in NNRTI vs PI and 1000 vs 30000 used analysis of covariance, adjusted for baseline VL; likelihood-based interval regression accounted for undetectable VL measurements. A sensitivity analysis was performed using multiple imputation to account for missing VLs at 
4 years. Logistic regression was used to analyse binary outcomes (e.g. VL $<400 \mathrm{c} / \mathrm{ml}$ at 4 years); continuous outcomes (e.g. CD4\%) used normal linear regression, analysis of adverse events used Poisson regression, difference in VL at switch used median regression, and time to event (e.g. switch) used Cox proportional-hazards regression. All major resistance mutations after baseline were accumulated(14), and differences tested using Poisson regression assuming children not fulfilling criteria for testing did not develop mutations; a sensitivity analysis, using multiple imputation to account for children with missing resistance tests, was performed. We undertook tests for interaction between the PI vs NNRTI and 1000 vs 30000 randomisations ( $<<0.05$ considered significant). Stata statistical software, version 11.1 (StataCorp, College Station, Texas, USA) was used throughout.

\section{Results}

A total of 266 children (133 Europe, 77 North America, 56 South America) from 68 centres in 13 countries were randomised between September 2002 and September 2005 (66 PI-1000, 65 PI-30000, 68 NNRTI-1000, 67 NNRTI-30000). Two children (both NNRTI-30000) withdrew consent before starting ART and one child had a major eligibility violation ( $\geq 56$ days prior ART, NNRTI-30000). Therefore, 263 children were included in analysis(Figure $1)$.

\section{Baseline Characteristics}

Baseline characteristics were balanced across both randomisations and are summarised in Table 1. Nosocomial transmission before 2 years of age (Romania) was the primary source of HIV-infection for 36 parenterally-infected children. ART for reduction of mother-tochild-transmission was used in 39(15\%), balanced across randomised groups. Only 5(2\%) children received single-dose nevirapine (before protocol amendment); the majority received zidovudine prophylaxis alone. Among 239(91\%) baseline samples tested retrospectively for resistance, $10(4 \%)$ had $\geq 1$ major mutation.

\section{Initial ART}

All children commenced ART after randomisation; 84\% within 3 days, maximum delay 63 days. $4(2 \%)$ children started with a regimen different from their allocation (2 PI, 2 NNRTI) either due to drug non-availability or refusal(Table 1). In the PI group, $49 \%$ started lopinavir/ritonavir and 48\% nelfinavir; in the NNRTI group, $61 \%$ started efavirenz and $38 \%$ nevirapine. As NRTIs, most children received lamivudine(88\%), with either zidovudine $(43 \%)$, abacavir( $24 \%)$ or stavudine $(20 \%)$.

\section{Follow-up}

234(89\%) children were in follow-up at 4 years, the primary end-point. At end-of-study (31 August 2009), median follow-up was 5.0 years (IQR: 4.2-6.0, range 0.1-6.7), with $218(83 \%)$ children still in follow-up, 38(14\%) lost to follow-up, 6(2\%) withdrawn consent, and 1 died(Figure 1).

At trial end, 188(71\%) children were on first-line ART. Of 75(29\%) who stopped first-line ART, 60 (28 PI, 32 NNRTI; 37 1000, 23 30000) had switched to second-line ART (4 subsequently started third-line) and 15 had discontinued ART after their first-line regimen (10 subsequently lost to follow-up)(Figure 1). Only 4 children were on nelfinavir at trial end; 36 had substituted lopinavir/ritonavir (32 at the 2007 nelfinavir recall(15)), 22 had switched to second-line and 2 had discontinued ART. Overall, 87(33\%) children substituted drugs while on first-line ART (mainly for toxicity/nelfinavir recall). 


\section{Switch to Second-line ART}

$37 / 60(62 \%)$ children switched to second-line ART at the protocol-defined switch-point (36 met virologic criteria and one met clinical criteria); 12(20\%; 1 PI, 11 NNRTI) switched before the strictly defined switch-point and 11(18\%; 9 PI, 2 NNRTI) switched after. A further 11 (8 PI, 3 NNRTI) children reached their protocol switch-point but did not switch(Figure 1, Table S1).

Median VL at switch to second-line ART was 6720c/ml (IQR:1380-26100) for the 1000 group, compared to $35712 \mathrm{c} / \mathrm{ml}$ (IQR:8060-72800) for the 30000 group (difference $0.73 \log _{10} \mathrm{c} / \mathrm{ml}, 95 \% \mathrm{CI}[0.41,1.04] ; \mathrm{p}=0.002$ ). Children in the 30000 group switched later $(\mathrm{HR}=0.58,95 \% \mathrm{CI}[0.34,0.98] ; \mathrm{p}=0.04)$; the estimated time until $10 \%$ of children following the $\geq 1000 \mathrm{c} / \mathrm{ml}$ strategy had switched was 54 weeks, whereas this was 95 weeks for children following the $\geq 30000 \mathrm{c} / \mathrm{ml}$ strategy(Figure 2). Mean CD4\% at switch did not differ between the groups (27\% vs $23 \%$ in 1000 vs 30000; difference $-3.6 \%, 95 \% \mathrm{CI}[-9.1,2.0] ; \mathrm{p}=0.07$ ) and residual viraemia as measured by the time-averaged area-under-the-VL-curve above $400 \mathrm{c} /$ $\mathrm{ml}$ after 24 weeks was also similar (mean(SD) $0.28(0.52)$ vs $0.27(0.49) \log _{10} \mathrm{c} / \mathrm{ml}$ in 1000 vs $30000 ; \mathrm{p}=0.90$ ).

\section{Primary Outcome}

Mean VL changes from baseline to 4 years, assessed on 234(89\%) randomised children, were -3.16 vs $-3.31 \log _{10} \mathrm{c} / \mathrm{ml}$ for PI vs NNRTI, respectively (difference $-0.15 \log _{10} \mathrm{c} / \mathrm{ml}$, $95 \% \mathrm{CI}[-0.41,0.11] ; \mathrm{p}=0.26$ ), and $-3.26 \mathrm{vs}-3.20 \log _{10} \mathrm{c} / \mathrm{ml}$ for $1000 \mathrm{vs} 30000$, respectively (difference $0.06 \log _{10} \mathrm{c} / \mathrm{ml}, 95 \% \mathrm{CI}[-0.20,0.32] ; \mathrm{p}=0.56$, Table S1). Sensitivity analysis, imputing missing data at 4 years, gave very similar results.

\section{Virological Outcomes}

During follow-up, there were no differences between randomised groups in the proportion $<400 \mathrm{c} / \mathrm{ml}$ (PI vs NNRTI $\mathrm{p}=0.77 ; 1000$ vs $30000 \mathrm{p}=0.53$ ) or $<50 \mathrm{c} / \mathrm{ml}$ (PI vs NNRTI $\mathrm{p}=0.35$; 1000 vs $30000 \mathrm{p}=0.41$ )(Figures 3a,b). At week 24, there was a trend towards a higher proportion $<400 \mathrm{c} / \mathrm{ml}$ on first-line ART in the NNRTI group (80\%) compared to PI (73\%, $\mathrm{OR}=1.49,95 \% \mathrm{CI}[0.82,2.72] ; \mathrm{p}=0.18)$, however at 4 years differences between randomised groups were negligible $(82 \% \mathrm{PI}, 82 \%$ NNRTI, OR=0.97,95\%CI[0.49,1.91];p=0.91; 83\% $1000,80 \% 30000, \mathrm{OR}=0.83,95 \% \mathrm{CI}[0.42,1.63] ; \mathrm{p}=0.42)$. In addition, the proportion $<400 \mathrm{c} /$ $\mathrm{ml}$ at 4 years was similar for all initial PIs and NNRTIs (80\% lopinavir/ritonavir, $84 \%$ other PIs (mainly nelfinavir), $80 \%$ efavirenz, $84 \%$ nevirapine).

At trial end, 149(57\%) children had continued VL suppression on first-line ART, with no difference by class (74(56\%) PI vs 75(57\%) NNRTI; HR=0.97,95\%CI[0.67,1.40]; $=0.84$ ). Only $18(7 \%)$ children had failed second-line ART, with similar failure rates across both randomisations $(10(8 \%) \mathrm{PI}, 8(6 \%) \mathrm{NNRTI}, \mathrm{HR}=0.78,95 \% \mathrm{CI}[0.31,1.97] ; \mathrm{p}=0.57 ; 11(8 \%)$ $1000,7(5 \%) 30000, \mathrm{HR}=0.62,95 \%$ CI $[0.24,1.59] ; \mathrm{p}=0.34)$.

\section{Immunological Outcomes and Growth}

Mean increases in CD4\% from baseline to 4 years were $13.7 \%$ vs $15.2 \%$ for PI vs NNRTI (difference $1.5 \%, 95 \% \mathrm{CI}[-0.7,3.7] ; \mathrm{p}=0.19$ ), and $15.1 \%$ vs $13.9 \%$ for 1000 vs 30000 (difference $-1.1 \%, 95 \% \mathrm{CI}[-3.4,1.1] ; \mathrm{p}=0.27$ )(Figure $3 \mathrm{c}$ ). Mean weight-for-age $\mathrm{z}$-score increased from baseline to 4 years by 0.53 vs 0.77 for PI vs NNRTI ( $\mathrm{p}=0.05$ ), and 0.73 vs 0.58 for 1000 vs $30000(\mathrm{p}=0.21)$. Mean height-for-age $\mathrm{z}$-score increases were 0.61 vs 0.74 for PI vs NNRTI ( $\mathrm{p}=0.27)$, and 0.65 vs 0.70 for 1000 vs $30000(\mathrm{p}=0.66)$. 


\section{Adverse Events and Disease Progression}

Ninety-seven grade $3 / 4$ adverse events were reported in 60 children, with no differences across randomisations (28 PI, $32 \mathrm{NNRTI}$, rate-ratio $=1.12,95 \% \mathrm{CI}[0.68,1.87] ; \mathrm{p}=0.72 ; 30$ 1000,3030000 , rate-ratio $=1.05,95 \% \mathrm{CI}[0.63,1.73] ; \mathrm{p}=0.98$ )(Table S2). Only 17 grade $3 / 4$ adverse events (in 17 children) required modification of ART. Sixty-nine serious adverse events(SAEs) occurred in 48 children, only one was life-threatening (acute renal failure, non-ART related, PI-30000). The number of children experiencing an SAE did not differ significantly between groups (23 PI, 25 NNRTI, $\mathrm{p}=0.84 ; 19$ 1000, 29 30000, $\mathrm{p}=0.09$ ).

One child died (NNRTI-1000) at week 277 due to presumptive malignancy. Fourteen new CDC stage C events (CMV (2), MAI (1), sepsis/pneumonia (6), cryptosporidiosis (1), oesophageal candidiasis (2), PCP (1), lymphoma (1)) occurred in 9 children (3 PI-1000, 3 PI-30000, 1 NNRTI-1000, 2 NNRTI-30000).

\section{Resistance}

Of the 108 children who met criteria for resistance testing, 91(84\%) had tests performed on 128 samples. Children randomised to switch at $\geq 1000 \mathrm{c} / \mathrm{ml}$ compared to $\geq 30000 \mathrm{c} / \mathrm{ml}$ developed a similar number of PI ( $\geq 1$ mutation: 11 1000, 5 30000, rateratio $=0.62,95 \% \mathrm{CI}[0.27,1.42] ; \mathrm{p}=0.27)$ and NNRTI ( $\geq 1$ mutation: 21 1000, 2130000 , rateratio $=1.15,95 \% \mathrm{CI}[0.73,1.80] ; \mathrm{p}=0.50)$ resistance mutations. However, there was a suggestion of an interaction between ART strategy and VL threshold for NNRTI mutations $(\mathrm{p}=0.02)$ as children in NNRTI-30000 developed more mutations than NNRTI-1000, but children in PI-30000 developed fewer than PI-1000(Table S1); this may reflect children in PI-1000 switching faster to NNRTI second-line and then VL failure. PI resistance was mainly in children initiating nelfinavir; only one child who initiated lopinavir/ritonavir developed PI resistance (low-level, V82A). Only 3 children (1 1000, 2 30000) developed high-level resistance to etravirine(Table 2).

For NRTI resistance, there was evidence of an interaction ( $\mathrm{p}=0.003$ ), with children randomised to NNRTIs and switch at $\geq 30000 \mathrm{c} / \mathrm{ml}$ developing more mutations ( $\geq 1$ mutation: 12 PI-1000, 9 PI-30000, rate-ratio=0.71,95\%CI[0.37,1.34]; $p=0.31 ; 14$ NNRTI-1000, 19 NNRTI-30000, rate-ratio $=2.53,95 \% \mathrm{CI}[1.44,4.45] ; \mathrm{p}=0.001)$. NRTI resistance was mainly M184V/I (lamivudine/emtricitabine), with few major resistance mutations to didanosine, abacavir or tenofovir. However, in the NNRTI-30000 group, more children developed $\geq 3$ NRTI mutations, conferring high-level resistance to zidovudine, didanosine, stavudine or abacavir(Table 2). Among children initiating ART with lopinavir/ritonavir, no increase in NRTI resistance was observed among PI-30000 (1 M184V, 1 M184V+thymidine-analogue mutations(TAMs)) compared with PI-1000 (4 M184V, 1 M184V+TAM+L74V/Y115F).

Sensitivity analysis, imputing data for children with missing resistance tests, gave very similar results.

\section{Discussion}

PENPACT-1 is the first paediatric trial to compare the long-term virologic, immunologic and clinical outcome of initiating ART with PI vs NNRTI-containing regimens. Previous trials in adults comparing efavirenz with nelfinavir (INITIO(16), ACTG 384(17)), and efavirenz with lopinavir/ritonavir (ACTG 5142(18)) as initial ART regimens showed superior VL efficacy of efavirenz compared with both these PIs. In our smaller pragmatic paediatric trial, clinicians could choose which PI and NNRTI to use; most children were on either nelfinavir or lopinavir/ritonavir as the PI, and nevirapine or efavirenz as the NNRTI. When the trial started, nelfinavir was the main PI available for children and owing to recall of specific batches in 2007 (chemical impurity(15)), by trial end most children who had not 
already switched to second-line had changed nelfinavir to lopinavir/ritonavir. Our finding of almost identical rates of viral load suppression for nelfinavir and lopinavir/ritonavir at 4 years, and rates very similar to starting with an NNRTI, suggest there is no difference between initiating ART with PI or NNRTI-based regimens in children. NRTI backbones in PENPACT-1 were similarly distributed in PI and NNRTI arms, important as we previously demonstrated superiority of abacavir-containing over zidovudine/lamivudine backbones in HIV-infected children initiating ART in the PENTA 5 trial $(19,20)$. Considering that this trial started in 2002 with regimens containing drugs such as nelfinavir which would not be considered optimal today(21), long-term viral, immunological and clinical responses were good; the large majority of children responded well over an average of 5 years; $71 \%$ were still on first-line at trial end, and only $7 \%$ failed second-line therapy. Few children modified drugs for grade $3 / 4$ toxicity and by trial end only one child (very immunosuppressed at baseline) had died. The small number of new CDC stage $\mathrm{C}$ events were equally divided between the randomised strategies.

We used a factorial design to also address the question of 'when to switch' ART. Although the trial was not formally powered to detect interactions between initial ART and VL threshold strategies, it provided a unique opportunity to study the 'when to switch' question efficiently, which has never been addressed in a large trial in adults or children. Forty-seven ART-experienced adults with VL $200-10000 \mathrm{c} / \mathrm{ml}$ were enrolled in a small pilot trial (ACTG A5115(10)) between 2002 and 2004, randomising to switch immediately or to defer switching until VL rose to $\geq 10000 \mathrm{c} / \mathrm{ml}$ or CD4 decreased by $>20 \%$. Patients were on a variety of ART regimens and were highly ART experienced. Those in the deferred arm remained immunologically stable over $\sim 60$ weeks but acquired more resistance mutations. The authors concluded that delaying switching was a possible strategy if future drug options were limited.

The rationale for choosing the VL switch criteria in PENPACT-1 was pragmatic. At the time of design, $1000 \mathrm{c} / \mathrm{ml}$ was increasingly adopted to define virologic failure and prompt switch to second-line therapy in adults. This was not routine practice amongst paediatricians who had concerns about 'running out' of drugs. UK/Irish observational data showed median switch VL was much higher than $1000 \mathrm{c} / \mathrm{ml}$ and no clear VL threshold triggered switch(22). An upper threshold of $30000 \mathrm{c} / \mathrm{ml}$ was chosen for the randomised comparison because this was $1.5 \log _{10} \mathrm{c} / \mathrm{ml}$ higher than $1000 \mathrm{c} / \mathrm{ml}$, thus above the range of assay variation and considered acceptable in contemporary practice. During the trial, reports from adult cohort studies suggested that individuals continuing the same treatment with detectable viraemia accumulated increasing resistance mutations, especially with NNRTI-based therapy $(23,24)$, which raised concern that practitioners might not follow the 30000 switch strategy.

However, although more switches occurred below $30000 \mathrm{c} / \mathrm{ml}$ in the NNRTI-30000 compared with the PI-30000 group, the VL at switch was maintained at the intended level.

We found no difference in 4-year VL between the $\geq 1000$ and $\geq 30000 \mathrm{c} / \mathrm{ml}$ switching groups. Furthermore, we observed no significant difference in accumulated major PI or NNRTI mutations between the two groups. Whereas NNRTI resistance was relatively common, PI resistance was infrequent, and occurred mainly in those initiating nelfinavir in accordance with other data(21, 25, 26); only one child who initiated lopinavir/ritonavir developed lowlevel PI resistance (V82A). Most children who developed NNRTI resistance had only 1 mutation; only 3 had high-level resistance to etravirine (one in the NNRTI-1000 group). Thus NNRTI mutations were likely selected early during viral rebound, before VL reached $1000 \mathrm{c} / \mathrm{ml}$, with few additional mutations occurring over the additional year it took for VL to reach $30000 \mathrm{c} / \mathrm{ml}$. These findings are consistent with recent data from the UK in which major mutations were detected at $<1000 \mathrm{c} / \mathrm{ml}(27)$. 
For NRTI resistance, there was an interaction between initial ART and VL threshold strategies. Examining the switching groups separately according to whether ART was initiated with PI or NNRTI, showed that more major mutations developed in the NNRTI-30000 group; 3 or more TAMs were only seen in this group. Over an average of 5 years, continuing NNRTI-based ART until VL increased to 30000c/ml selected the M184V/ I mutation in $\sim 10 \%$ more of all randomised children ( $25 \%$ of those with a resistance test) and significant mutations to other NRTI drugs in an additional $5 \%$ (14\% of those tested). In contrast, development of resistance to NRTIs appeared to be largely prevented by the presence of lopinavir/ritonavir in both the PI-30000 and PI-1000 groups, and resistance which did occur was mainly to lamivudine (both children with TAMs/L74V/Y115F had multiple regimen changes and never suppressed virologically).

What do the PENPACT-1 trial results mean for long-term ART strategies for HIV-infected children, particularly in resource-limited settings, where most now live and where drug options are limited and VL monitoring facilities mostly unavailable? First, long-term virological, clinical and immunological outcomes, even to suboptimal ART, are excellent, even when starting at relatively low CD4 ( $41 \%$ had CD4 <15\%). Second, development of NNRTI resistance cannot be readily prevented even with regular 3-monthly VL monitoring as it occurs very soon after VL rebound; however, continuing on a failing NNRTI regimen is likely to increase accumulation of NRTI mutations, compromising their subsequent use. Third, results of our trial raise the question, not directly addressed here, as to whether infants starting lopinavir/ritonavir as currently recommended if perinatally exposed to single-dose nevirapine for reduce mother-to-child transmission, might delay switching at virological failure rather than switch to an NNRTI+2NRTI second-line regimen, where rapid development of resistance may be a risk if NNRTI mutations have been archived. Further research in this area is needed. Finally, if NRTIs become superseded by new drugs, such that they no longer have a place in second or subsequent lines of ART, then the role for VL or resistance monitoring on ART might be less important as new regimens can be given with no overlapping resistance.

In conclusion, in the absence of single-dose nevirapine prophylaxis for reduction of motherto-child transmission and anticipated poor adherence (e.g. during adolescence), there is no difference between PI and NNRTI-containing initial ART regimens in children; both result in good long-term viral load, immunological and clinical outcomes. Delaying switching until VL levels are $\geq 30000 \mathrm{c} / \mathrm{ml}$ results in accumulation of more NRTI mutations with NNRTIcombination therapy compared with switching at $\geq 1000 \mathrm{c} / \mathrm{ml}$; conversely, for children on PIbased ART, the absence of a difference in the NRTI/PI resistance suggests that delayed switching may be reasonable in circumstances and settings where future drug options are limited.

\section{Panel discussion}

The only previous randomised trial comparing different viral load thresholds for switching from first- to second-line ART was in adults and failed to complete recruitment (ACTG A5115). Several trials have compared starting ART with PI versus NNRTI-based regimens in HIV-infected adults. The largest of these trials (including ACTG 384, ACTG 5142, INITIO, FIRST, ATLANTIC) have had different end-points and some have been drug specific; viral load responses have been slightly superior for efavirenz versus PI in some trials, but CD4 responses have been similar. In children, PENPACT-1 is the first long-term trial comparing PI versus NNRTI-based ART across all ages of children, the majority of whom have not been exposed to perinatal NNRTIs. The only other paediatric trials to report have been in young children with perinatal NNRTI exposure: in this subgroup, IMPAACT 1060 found lopinavir/ritonavir was superior to nevirapine, and NEVEREST found that switching from lopinavir/ritonavir after achieving viral suppression to nevirapine resulted in 
higher rates of viral suppression $(<50 \mathrm{c} / \mathrm{ml})$ than staying on lopinavir/ritonavir, but of the children who did not suppress, more of those in the switch to nevirapine group had viral rebound $(>1000 \mathrm{c} / \mathrm{ml})$ than those who stayed on lopinavir/ritonavir.

\section{Supplementary Material}

Refer to Web version on PubMed Central for supplementary material.

\section{Acknowledgments}

Details of funding

The PENPACT-1 trial was sponsored jointly by the Paediatric European Network for Treatment of AIDS (PENTA) Foundation, Agènce Nationale de Recherche sur le Sida et les hepatites virales (ANRS) and the Pediatric AIDS Clinical Trials Group (PACTG), subsequently the International Maternal Pediatric Adolescent AIDS Clinical Trials Group (IMPAACT).

Overall support for PACTG/IMPAACT was provided by the National Institute of Allergy and Infectious Diseases (NIAID) [U01 AI068632], the Eunice Kennedy Shriver National Institute of Child Health and Human Development (NICHD), and the National Institute of Mental Health (NIMH) [AI068632]. The content is solely the responsibility of the authors and does not necessarily represent the official views of the NIH. This work was supported by the Statistical and Data Analysis Center at Harvard School of Public Health, under the National Institute of Allergy and Infectious Diseases cooperative agreement \#5 U01 AI41110 with the PACTG and \#1 U01 AI068616 with the IMPAACT Group. Support of the sites was provided by the National Institute of Allergy and Infectious Diseases (NIAID) and the NICHD International and Domestic Pediatric and Maternal HIV Clinical Trials Network funded by NICHD (contract number N01-DK-9-001/HHSN267200800001C).

PENTA is a coordinated action of the European Commission, supported by the sixth framework contract number LSHP-CT-2006-018865 and fifth framework program contract number QLK2-CT-2000-00150 and by the PENTA Foundation. UK clinical sites were supported by a grant from the MRC; those in Italy by a grant from the Istituto Superiore di Sanita` - Progetto Terapia Antivirale 2004, 2005. GSK and BMS provided drugs in Romania.

The trial was coordinated by four trials centres: the Medical Research Council (MRC) Clinical Trials Unit, London, UK (with support from the MRC); INSERM SC10, Paris, France (supported by ANRS); Frontier Science, New York, USA; and Westat, Maryland, USA (supported by NICHD).

Contributory Listings (alphabetical)

The PENPACT-1 trial was designed by AB, AC, CG, DMG, MH, RM, AM, LM, YS and GTW.

The trial was co-ordinated in North America by MH, RM, AM, LM and MES, and in Europe/South America by $\mathrm{AB}, \mathrm{HC}, \mathrm{AC}, \mathrm{CG}, \mathrm{DMG}$, LHarp, YS and GTW.

HC and ASW performed Data and Safety Monitoring Board analyses, overseen by AB and MH. AB, HC, LHarr and $\mathrm{MH}$ wrote the trial analysis plan, which all authors reviewed; $\mathrm{HC}$ and LHarr conducted the final analysis. All members of the writing committee contributed to the interpretation of the data.

DMG, LHarr, AM and GTW wrote the first draft of the paper. All authors commented extensively, revised the manuscript critically and approved the final version.

\section{Funding}

Paediatric European Network for Treatment of AIDS(PENTA); Pediatric AIDS Clinical Trials Group(PACTG/ IMPAACT).

\section{References}

1. Palella FJ Jr, Delaney KM, Moorman AC, Loveless MO, Fuhrer J, Satten GA, et al. Declining morbidity and mortality among patients with advanced human immunodeficiency virus infection. HIV Outpatient Study Investigators. N Engl J Med. 1998 Mar 26; 338(13):853-60. [PubMed: 9516219] 
2. Vigouroux C, Gharakhanian S, Salhi Y, Nguyen TH, Adda N, Rozenbaum W, et al. Adverse metabolic disorders during highly active antiretroviral treatments (HAART) of HIV disease. Diabetes Metab. 1999 Nov; 25(5):383-92. [PubMed: 10592860]

3. Faye A, Bertone C, Teglas JP, Chaix ML, Douard D, Firtion G, et al. Early multitherapy including a protease inhibitor for human immunodeficiency virus type 1-infected infants. Pediatr Infect Dis J. 2002 Jun; 21(6):518-25. [PubMed: 12182375]

4. Luzuriaga K, McManus M, Mofenson L, Britto P, Graham B, Sullivan JL. A trial of three antiretroviral regimens in HIV-1-infected children. N Engl J Med. 2004 Jun 10; 350(24):2471-80. [PubMed: 15190139]

5. Funk MB, Linde R, Wintergerst U, Notheis G, Hoffmann F, Schuster T, et al. Preliminary experiences with triple therapy including nelfinavir and two reverse transcriptase inhibitors in previously untreated HIV-infected children. AIDS. 1999 Sep 10; 13(13):1653-8. [PubMed: 10509566]

6. Watson DC, Farley JJ. Efficacy of and adherence to highly active antiretroviral therapy in children infected with human immunodeficiency virus type 1. Pediatr Infect Dis J. 1999 Aug; 18(8):682-9. [PubMed: 10462336]

7. Working Group on Antiretroviral Therapy and Medical Management of HIV-Infected Children. Guidelines for the use of antiretroviral agents in pediatric HIV infection. U.S. Department of Health and Human Services; 2009. http://aidsinfo.nih.gov/ContentFiles/PediatricGuidelines.pdf

8. World Health Organization. Antiretroviral therapy for HIV infection in infants and children: towards universal access. Recommendations for a public health approach (2010 revision). [cited 14th September 2010]; Available from: http://www.who.int/hiv/pub/paediatric/infants2010/en/index.html

9. Paediatric European Network for Treatment of AIDS (PENTA). PENTA 2009 guidelines for the use of antiretroviral therapy in paediatric HIV-1 infection. HIV Med. 2009 Nov; 10(10):591-613. [PubMed: 19878352]

10. Riddler SA, Jiang H, Tenorio A, Huang H, Kuritzkes DR, Acosta EP, et al. A randomized study of antiviral medication switch at lower- versus higher-switch thresholds: AIDS Clinical Trials Group Study A5115. Antivir Ther. 2007; 12(4):531-41. [PubMed: 17668562]

11. Johnson VA, Brun-Vezinet F, Clotet B, Gunthard HF, Kuritzkes DR, Pillay D, et al. Update of the drug resistance mutations in HIV-1: December 2009. Top HIV Med. 2009 Dec; 17(5):138-45. [PubMed: 20068260]

12. Stanford University HIV Drug Resistance Database. [cited 14 September 2010]; Available from: http://hivdb.stanford.edu/

13. Hughes MD. Analysis and design issues for studies using censored biomarker measurements with an example of viral load measurements in HIV clinical trials. Stat Med. 2000 Dec 15; 19(23): 3171-91. [PubMed: 11113952]

14. Pillay D, Green H, Matthias R, Dunn D, Phillips A, Sabin C, et al. Estimating HIV-1 drug resistance in antiretroviral-treated individuals in the United Kingdom. Journal of Infectious Diseases. 2005 Sep 15; 192(6):967-73. [PubMed: 16107948]

15. Roche Media Release. Roche recalls Viracept due to chemical impurity. June 6th. 2007 [cited 30th September 2010; Available from: http://www.roche.com/med-cor-2007-06-06b

16. Yeni P, Cooper DA, Aboulker JP, Babiker AG, Carey D, Darbyshire JH, et al. Virological and immunological outcomes at 3 years after starting antiretroviral therapy with regimens containing non-nucleoside reverse transcriptase inhibitor, protease inhibitor, or both in INITIO: open-label randomised trial. Lancet. 2006 Jul 22; 368(9532):287-98. [PubMed: 16860698]

17. Shafer RW, Smeaton LM, Robbins GK, De Gruttola V, Snyder SW, D’Aquila RT, et al. Comparison of four-drug regimens and pairs of sequential three-drug regimens as initial therapy for HIV-1 infection. N Engl J Med. 2003 Dec 11; 349(24):2304-15. [PubMed: 14668456]

18. Riddler SA, Haubrich R, DiRienzo AG, Peeples L, Powderly WG, Klingman KL, et al. Classsparing regimens for initial treatment of HIV-1 infection. N Engl J Med. 2008 May 15; 358(20): 2095-106. [PubMed: 18480202]

19. Paediatric European Network for Treatment of AIDS (PENTA). Comparison of dual nucleosideanalogue reverse-transcriptase inhibitor regimens with and without nelfinavir in children with 
HIV-1 who have not previously been treated: the PENTA 5 randomised trial. Lancet. 2002 Mar 2; 359(9308):733-40. [PubMed: 11888583]

20. Green H, Gibb DM, Walker AS, Pillay D, Butler K, Candeias F, et al. Lamivudine/abacavir maintains virological superiority over zidovudine/lamivudine and zidovudine/abacavir beyond 5 years in children. AIDS. 2007 May 11; 21(8):947-55. [PubMed: 17457088]

21. Walmsley S, Bernstein B, King M, Arribas J, Beall G, Ruane P, et al. Lopinavir-ritonavir versus nelfinavir for the initial treatment of HIV infection. N Engl J Med. 2002 Jun 27; 346(26):2039-46. [PubMed: 12087139]

22. Lee, KJ.; Lyall, EGH.; Walker, AS.; Sharland, M.; Judd, A.; Gibb, DM., et al. Wide disparity in switch to second-line therapy in HIV-infected children in CHIPS. Eighth International Congress on Drug Therapy in HIV Infection; November 2006; Glasgow, UK.

23. Gupta R, Hill A, Sawyer AW, Pillay D. Emergence of drug resistance in HIV type 1-infected patients after receipt of first-line highly active antiretroviral therapy: a systematic review of clinical trials. Clin Infect Dis. 2008 Sep 1; 47(5):712-22. [PubMed: 18662137]

24. von Wyl V, Yerly S, Boni J, Burgisser P, Klimkait T, Battegay M, et al. Emergence of HIV-1 drug resistance in previously untreated patients initiating combination antiretroviral treatment: a comparison of different regimen types. Arch Intern Med. 2007 Sep 10; 167(16):1782-90. [PubMed: 17846398]

25. Hicks C, King MS, Gulick RM, White AC Jr, Eron JJ Jr, Kessler HA, et al. Long-term safety and durable antiretroviral activity of lopinavir/ritonavir in treatment-naive patients: 4 year follow-up study. AIDS. 2004 Mar 26; 18(5):775-9. [PubMed: 15075512]

26. Chakraborty R, Smith CJ, Dunn D, Green H, Duong T, Doerholt K, et al. HIV-1 drug resistance in HIV-1-infected children in the United Kingdom from 1998 to 2004. Pediatric Infectious Disease Journal. 2008 Mar 27; 27(5):457-9. [PubMed: 18382385]

27. Mackie NE, Phillips AN, Kaye S, Booth C, Geretti AM. Antiretroviral drug resistance in HIV-1infected patients with low-level viremia. J Infect Dis. 2010 May 1; 201(9):1303-7. [PubMed: 20350161]

\section{Appendix}

We thank all the children, families and staff from the centres participating in the PENPACT-1 trial.

\section{Writing Committee (alphabetical)}

Abdel Babiker, Hannah Castro (nee Green), Alexandra Compagnucci, Susan Fiscus, Carlo Giaquinto, Diana M Gibb, Lynda Harper, Linda Harrison, Michael Hughes, Ross McKinney, Ann Melvin, Lynne Mofenson, Yacine Saidi, M Elizabeth Smith, Gareth TudorWilliams, A Sarah Walker.

\section{PENPACT1 Protocol Team}

PACTG/IMPAACT/NICHD: P Brouwers, D Costello, E Ferguson, S Fiscus, J Hodge, M Hughes, C Jennings, A Melvin (Co-Chair), R McKinney (Co-Chair), L Mofenson, M Warshaw, ME Smith, S Spector, E Stiehm, M Toye, R Yogev.

PENTA: JP Aboulker, A Babiker, H Castro, A Compagnucci, A De Rossi, C Giaquinto, J Darbyshire, M Debré, DM Gibb, L Harper, L Harrison, N Klein, D Pillay, Y Saidi, G TudorWilliams (Co-Chair), AS Walker.

Data and Safety Monitoring Board: B Brody, C Hill, P Lepage, J Modlin, A Poziak, M Rein (Chair 2002-2003), M Robb (Chair 2004 - 2009), T Fleming, S Vella, KM Kim. 


\section{Clinical Sites}

Argentina: Hospital de Pediatria Dr JP Garrahan, Buenos Aires: R Bologna, D Mecikovsky, N Pineda, L Sen (L), A Mangano (L), S Marino (L), C Galvez (L); Laboratorio Fundai: G Deluchi (L). Austria: Universitätsklinik für Kinder und Jugendheilkunde, Graz: B Zöhrer, W Zenz, E. Daghofer, K Pfurtscheller, B Pabst (L).

Bahamas: Princess Margaret Hospital: MP Gomez, P McNeil, M Jervis, I Whyms, D Kwolfe, S Scott (P).

Brazil: University of Sao Paulo at Ribeirao Preto: MM Mussi-Pinhata, ML Issac, MC Cervi, BVM Negrini, TC Matsubara, C BSS de Souza (L), JC Gabaldi (P); Institute of Pediatrics (IPPMG), Federal University of Rio de Janeiro: RH Oliveira, MC Sapia, T Abreu, L Evangelista, A Pala, I Fernandes, I Farias, M de F Melo (L), H Carreira (P), LM Lira (P); Instituto de Infectologia Emilio Ribas, Sao Paolo: M della Negra, W Queiroz, YC Lian; DP Pacola; Fleury Laboratories; Federal University of Minas Gerais, Belo Horizonte: J Pinto, F Ferreira, F Kakehasi, L Martins, A Diniz, V Lobato, M Diniz, C Hill (L), S Cleto (L), S Costa (P), J Romeiro (P).

France: Hôpital d'enfants Armand Trousseau, Paris: C Dollfus, MD Tabone, MF Courcoux, G Vaudre A Dehée (L), A Schnuriger (L), N Le Gueyades (P), C De Bortoli (P); CHU Hôtel Dieu, Nantes: F Méchinaud, V Reliquet, J Arias (L), A Rodallec (L), E André (L), I Falconi (P), A Le Pelletier (P); Hôpital de l'Archet II, Nice, F Monpoux, J Cottalorda (L), S Mellul (L); Hôpital Jean Verdier, Bondy: E Lachassinne; Laboratoire de virologie-Hôpital Necker Enfants Malades, Paris: J Galimand (L), C Rouzioux (L), ML Chaix (L), Z Benabadji (P), M Pourrat (P); Hôpital Cochin Port-Royal- Saint Vincent de Paul, Paris: G Firtion, D Rivaux, M Denon, N Boudjoudi, F Nganzali, A Krivine (L), JF Méritet (L), G Delommois (L), C Norgeux (L), C Guérin (P); Hôpital Louis Mourier, Colombes: C Floch, L Marty, H Hichou (L), V Tournier (P); Hôpital Robert Debré, Paris, A Faye, I Le Moal, M Sellier (P), L Dehache (P); Laboratoire de virologie-Hôpital Bichat Claude Bernard-Paris: F Damond (L), J Leleu (L), D Beniken (L), G Alexandre-Castor (L)

Germany: Universitäts - Kinderklinik Düsseldorf: J Neubert, T Niehues, HJ Laws, K Huck, S Gudowius, (H Loeffler), S Bellert(L), A Ortwin (L); Universitäts - Kinderkliniken, Munich: G Notheis, U Wintergerst, F Hoffman, (A Werthmann, S Seyboldt, L Schneider, B Bucholz); Charité - Medizische Fakultät der Humboldt-Universität zu Berlin: C FeiternaSperling, C Peiser, R Nickel, T Schmitz, T Piening, C Müller (L); Kinder- und Jugendklinik, Universität Rostock: G Warncke, M Wigger, R Neubauer.

Ireland: Our Lady's Hospital for Sick Children, Dublin: K Butler, AL Chang, T Belger, A Menon, M O'Connell, L Barrett, A Rochford, M Goode, E Hayes, S McDonagy, A Walsh, A Doyle, J Fanning (P), M O'Connor (P), M Byrne (L), N O'Sullivan (L), E Hyland (L).

Italy: Clinica Pediatrica, Ospedale L Sacco, Milan: V Giacomet, A Viganò, I Colombo, D Trabattoni (L), A Berzi (L); Clinica Pediatrica, Università di Brescia: R Badolato, F Schumacher, V Bennato, M Brusati, A Sorlini, E Spinelli, M Filisetti, C Bertulli; Clinica Pediatrica, Università di Padova: O Rampon, C Giaquinto, M Zanchetta (L); Ospedale S. Chiara, Trento: A Mazza, G Stringari, G Rossetti (L); Ospedale del Bambino Gesù, Rome: S Bernardi, A Martino, G Castelli Gattinara, P Palma, G Pontrelli, H Tchidjou, A. Furcas, C. Frillici, A. Mazzei, A Zoccano (P), C Concato (L).

Romania: Spitalul Clinic de Boli Infectioase Victor Babes, Bucharest: D Duiculescu, C Oprea, G Tardei (L), F Abaab (P),; Institutul de Boli Infectioase Matei Bals, Bucharest: M Mardarescu, R Draghicenoiu, D Otelea (L), L Alecsandru (P); Clinic Municipal, Constanta: 
R Matusa, S Rugina, M Ilie, Silvia Netescu (P). Clinical monitors: C Florea, E Voicu, D Poalelungi, C Belmega, L Vladau, A Chiriac

Spain: Hospital Materno-Infantil 12 de Octubre, Madrid: JT Ramos Amador, MI Gonzalez Tomé, P Rojo Conejo, M Fernandez, R Delgado Garcia (L), JM Ferrari (P); Institute de Salud Carlos III, Madrid: M Garcia Lopez, MJ Mellado Peña, P Martin Fontelos, I Jimenez Nacher (P); Biobanco Gregorio Marañon, Madrid: MA Muñoz Fernandez (L), JL Jimenez (L), A García Torre (L); clinical monitors: M Penin, R Pineiro Perez, I Garcia Mellado.

UK: Bristol Royal Children's Hospital: A Finn, M LaJeunesse, E Hutchison, J Usher (L), L Ball (P), M Dunn (P); St. George's Healthcare NHS Trust, London: M Sharland, K Doerholt, S Storey, S Donaghy, C Wells (P), K Buckberry (P), P Rice (P); University Hospital of North Staffordshire: P McMaster, P Butler, C Farmer (L), J Shenton (P), H Haley (P), J Orendi (L), University Hospital Lewisham: J Stroobant, L Navarante, P Archer, C Mazhude, D Scott, R O'Connell, J Wong (L), G Boddy (P); Sheffield Children's Hospital: F Shackley, R Lakshman, J Hobbs, G Ball (L), G Kudesia (L), J Bane (P), D Painter (P); Ealing Hospital NHS Trust: K Sloper, V Shah, A Cheng (P), A Aali (L); King's College Hospital, London: C Ball, S Hawkins, D Nayagam, A Waters, S Doshi (P); Newham University Hospital: S Liebeschuetz, B Sodiende, D Shingadia, S Wong, J Swan (P), Z Shah (P); Royal Devon and Exeter Hospital: A Collinson, C Hayes, J King (L), K 0'Connor (L); Imperial College Healthcare NHS Trust, London: G Tudor-Williams, H Lyall, K Fidler, S Walters, C Foster, D Hamadache, C Newbould, C Monrose, S Campbell, S Yeung, J Cohen, N Martinez-Allier, D Melvin, J Dodge, S Welch, (G Tatum, A Gordon), S Kaye (L), D Muir (L), D Patel (P); Great Ormond Street Hospital: V Novelli, D Gibb, D Shingadia, K Moshal, J Lambert, N Klein, J Flynn, L Farrelly, M Clapson, L Spencer, M Depala (P); Institute of Child Health, London: M Jacobsen (L); John Radcliffe Hospital, Oxford: S Segal, A Pollard, S Yeadon, Y Peng (L), T Dong (L), Y Peng (L), K Jeffries (L), M Snelling (P), Nottingham University Hospitals: A Smyth, J Smith; Chelsea and Westminster Hospital, London: B Ward; UCLH, London: E Jungmann; Doncaster Royal Infirmary: C Ryan, K Swaby; Health Protection Agency, London: A Buckton (L); Health Protection Agency, Birmingham: E Smidt (L).

USA: Harlem Hospital Center: EJ Abrams, S Champion, AD Fernandez, D Calo, L Garrovillo, K Swaminathan, T Alford, M Frere, Columbia University laboratories, J Navarra (P, Town Total Health); NYU School of Medicine: W Borkowsky, S Deygoo, T Hastings, S Akleh, T Ilmet (L); Seattle Children's Hospital: A Melvin, K Mohan, G Bowen (Additional support by NIH Grant UL1 RR025014); University of South Florida: PJ Emmanuel, J

Lujan-Zimmerman, C Rodriguez, S Johnson, A Marion, C Graisbery, D Casey, G Lewis; All Children's Hospital laboratories; Oregon Health and Science University: J Guzman-Cottrill, R Croteau; San Juan City Hospital: M Acevedo-Flores, M Gonzalez, L Angeli; L Fabregas, Lab 053, P Valentin (P); SUNY- Upstate Medical University-Syracuse: L Weiner, KA Contello, W Holz, M Butler; SUNY, Health Science Center at Stonybrook: S Nachman, MA. Kelly, DM. Ferraro, UNC Retrovirology Lab; Howard University Hospital: S Rana, C Reed, E Yeagley, A Malheiro, J Roa; LAC and USC Medical Center: M Neely, A Kovacs, L Spencer, J Homans, Y Rodriguez Lozano, Maternal Child Virology Research Laboratory, Investigational Drug Service; South Florida Childrens Diagnostic \& Treatment Center: A Puga, G Talero, R Sellers; Broward General Medical Center, University of Miami (L); University College of Florida College of Medicine- Gainsville: R Lawrence; University of Rochester Pediatrics: GA. Weinberg, B Murante, S Laverty; Miller Children's Hospital Long Beach: A Deveikis, J Batra, T Chen, D Michalik, J Deville, K Elkins, S Marks, J Jackson Alvarez, J Palm, I Fineanganofo (L), M Keuth (L), L Deveikis (L), W Tomosada (P); Tulane University New Orleans: R Van Dyke, T Alchediak, M Silio, C Borne, S Bradford, S Eloby-Childress (L), K Nguyen (P); University of Florida/Jacksonville: MH. 
Rathore, A Alvarez; A Mirza, S Mahmoudi, M Burke; University of Puerto Rico: IL Febo, L Lugo, R Santos; Children's Hospital Los Angeles: JA Church, T Dunaway, C Rodier; St. Jude/UTHSC: P Flynn, N Patel, S DiScenza, M Donohoe; WNE Maternal Pediatric Adolescent AIDS: K Luzuriaga, D Picard; Texas Children's Hospital: M Kline, ME Paul, WT Shearer, C McMullen-Jackson; Children's Memorial Hospital, Chicago: R Yogev, E Chadwick, E Cagwin, K Kabat; New Jersey Medical School: A Dieudonne, P Palumbo, J Johnson; Robert Wood Johnson Medical School, New Brunswick : S Gaur, L Cerracchio; Columbia IMPAACT: M Foca, A Jurgrau, S Vasquez Bonilla, G Silva; Babies' Hospital, Columbia/Presbyterian Medical Center, New York (A Gershon); University of Massachusetts Medical Center, Worcester (J Sullivan); UCLA Medical Center, Los Angeles (Y Bryson); Children's Hospital, Seattle: L Frenkel; UNC-Chapel Hill Virology Lab: S Fiscus (L), J Nelson (L).

\section{Trials Units/Support}

INSERM SC10 Paris: JP Aboulker, A Compagnucci, G Hadjou, S Léonardo, Y Riault, Y Saïdi

MRC Clinical Trials Unit, UK: A Babiker, L Buck, JH Darbyshire, L Farrelly, S Forcat, DM Gibb, H Castro, L Harper, L Harrison, J Horton, D Johnson, S Moore, C Taylor, AS Walker.

Westat/NICHD: D Collins, S Buskirk, P Kamara, C Nesel, M Johnson, A Ferreira

Frontier Science: J Hodge, J Tutko, H Sprenger

IMPAACT: M. Hughes, M. Warshaw, P. Britto, C. Powell

NIAID: R DerSimonian, E Handelsman

PENTA Steering Committee: JP Aboulker, J Ananworanich, A Babiker, E Belfrage, S Bernardi, S Blanche, AB Bohlin, R Bologna, D Burger, K Butler, G Castelli-Gattinara, H Castro, P Clayden, A Compagnucci, JH Darbyshire, M Debré, R De Groot, M Della Negra, D Duiculescu, A Faye, C Giaquinto (Chair), DM Gibb, I Grosch-Wörner, L Harper, N Klein, M Lallemant, J Levy, H Lyall, M Marczynska, M Mardarescu, MJ Mellado Pena, D Nadal, T Niehues, C Peckham, D Pillay, JT Ramos Amador, L Rosado, R Rosso, C Rudin, Y Saïdi, H Scherpbier, M Sharland, M Stevanovic, C Thorne, PA Tovo, G Tudor-Williams, AS Walker, S Welch, U Wintergerst, N Valerius. 


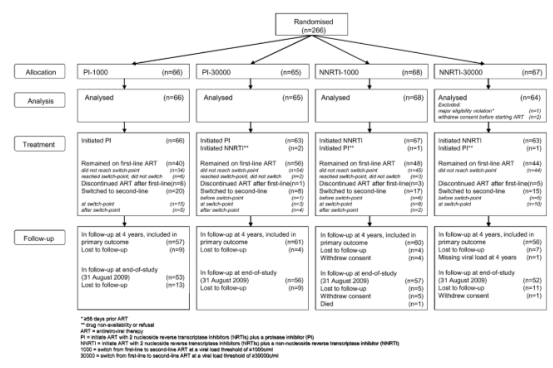

Figure 1.

PENPACT-1 participant flowchart 


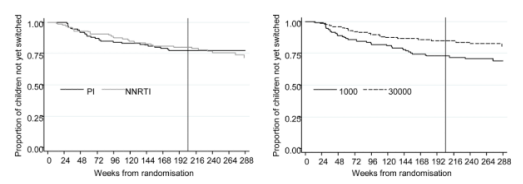

Figure 2.

Time to switch to second-line ART

Note: Data shown to week 288 when 91 children (43 PI, 48 NNRTI; 47 1000, 44 30000) were in follow-up. Vertical line indicates 4 years, primary end-point. 


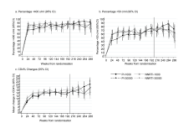

Figure 3.

Virological suppression and CD4\% changes during follow-up

Note: Data shown to week 288 when 91 children (43 PI, 48 NNRTI; 47 1000, 4430000 ) were in follow-up. Vertical line indicates 4 years, primary end-point. 


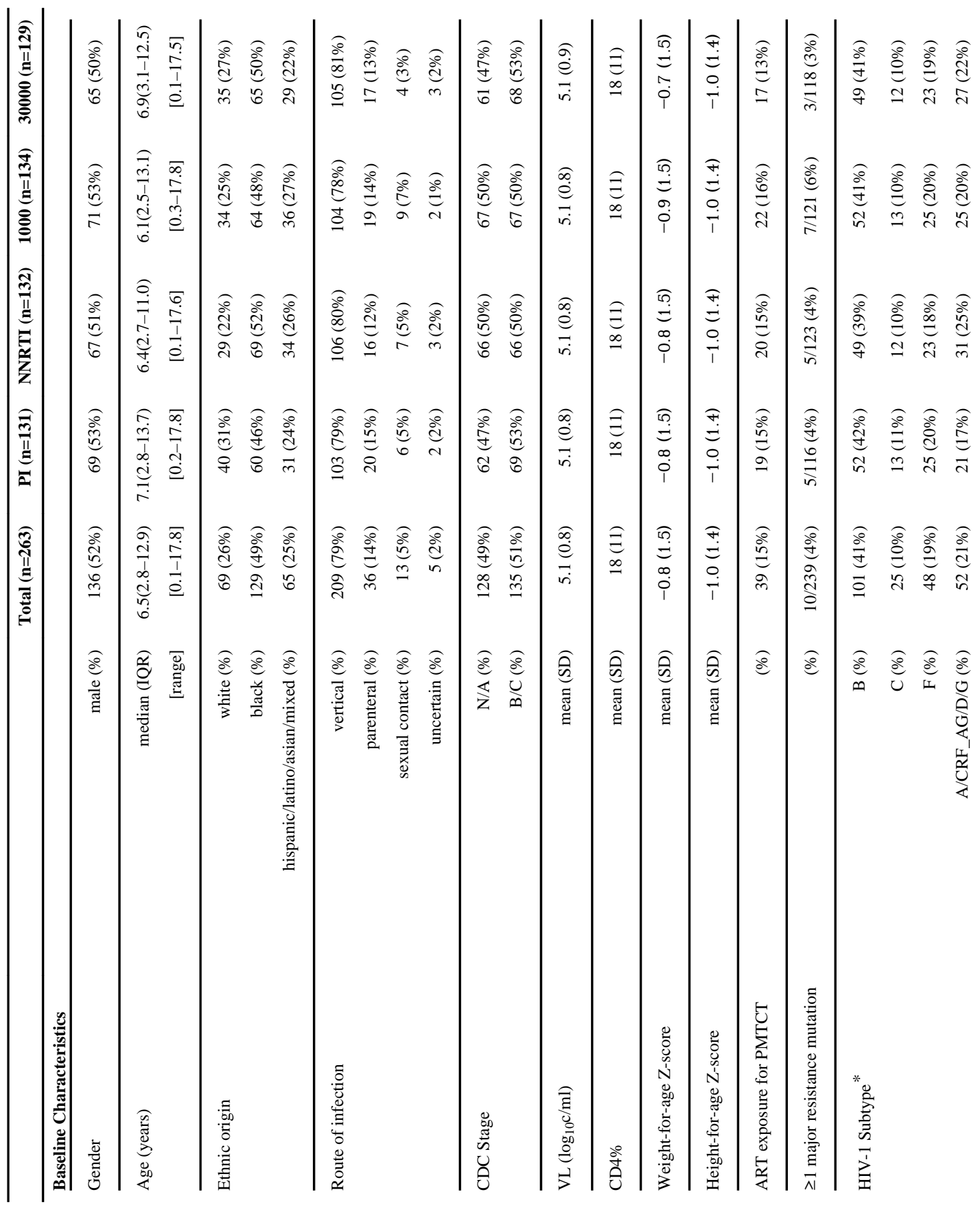




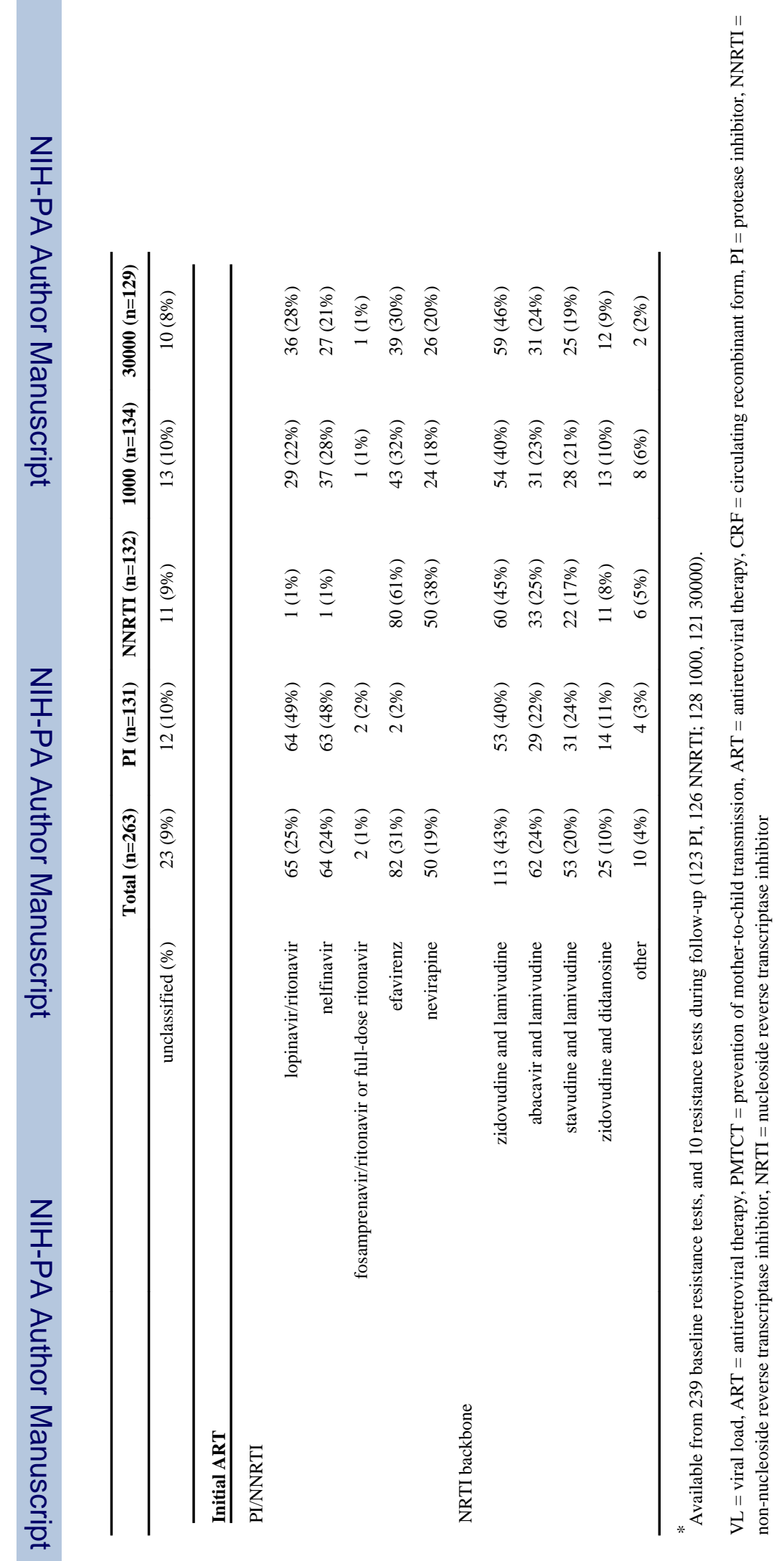



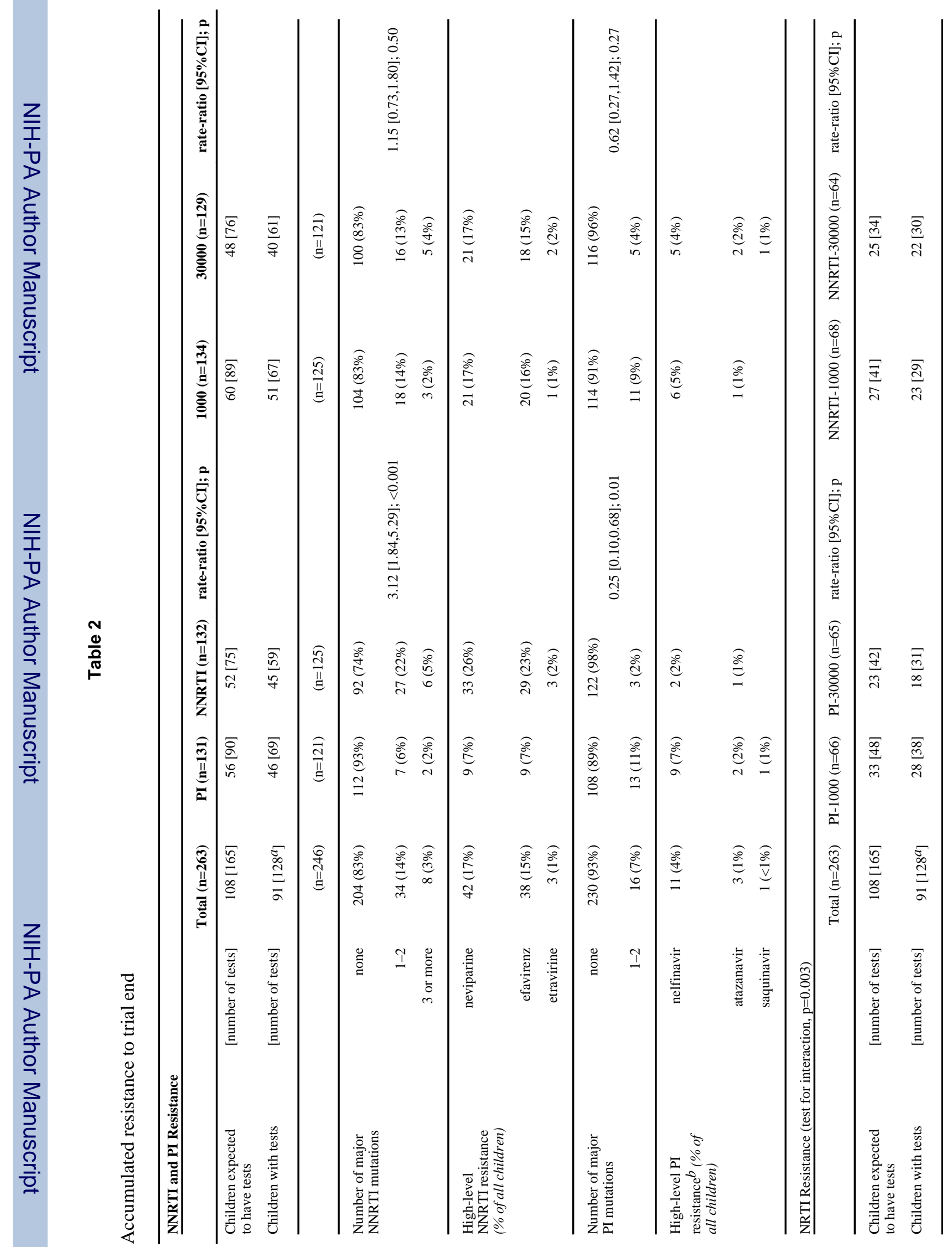

Lancet Infect Dis. Author manuscript; available in PMC 2012 April 1. 


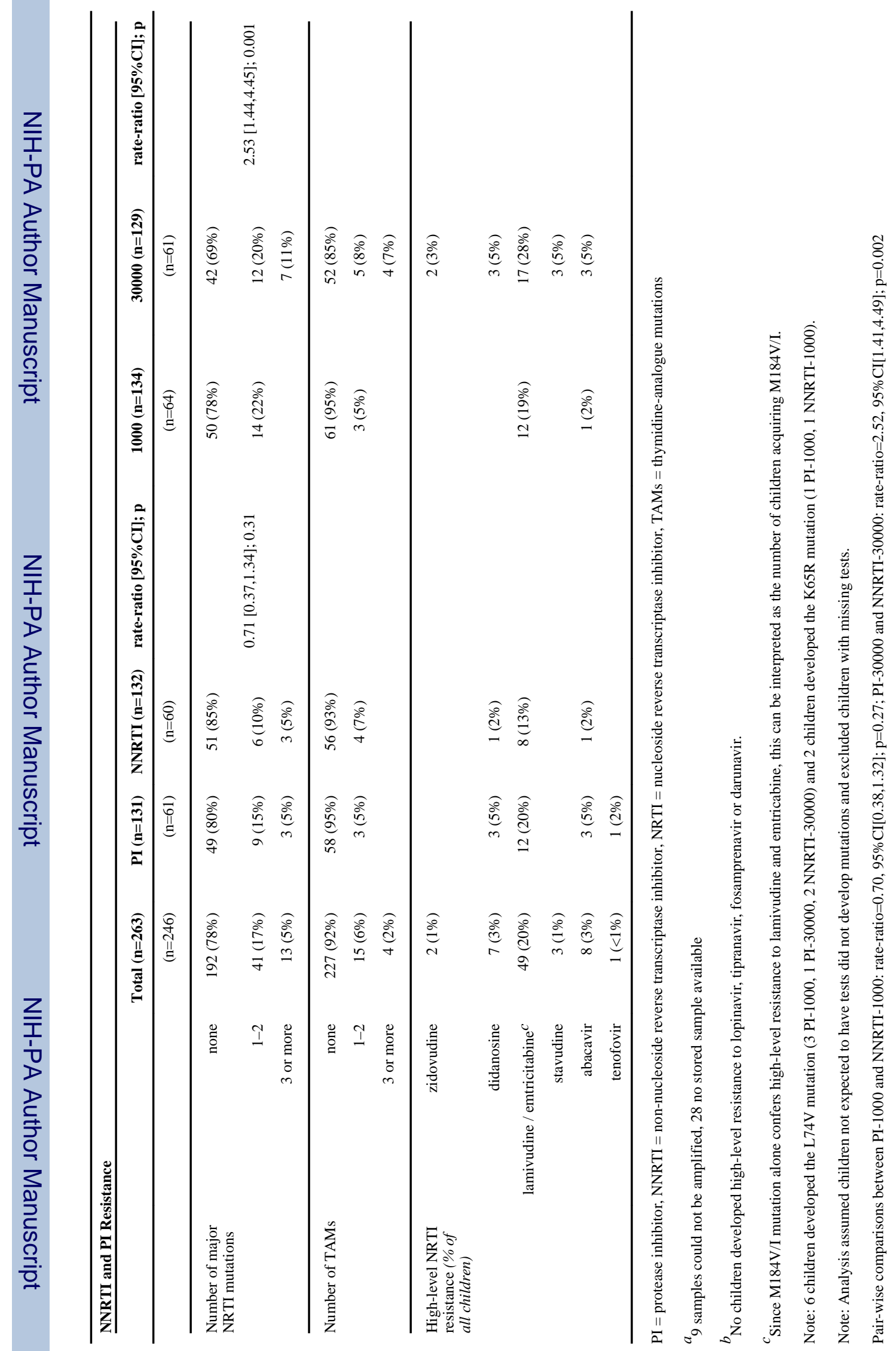

Lancet Infect Dis. Author manuscript; available in PMC 2012 April 1. 